\title{
Bilateral Kimura's disease of the eyelids
}

\author{
S M Kennedy, J F Pitts, W R Lee, D C Gibbons
}

\begin{abstract}
A case of Kimura's disease affecting the eyelids bilaterally is reported in a 5-year-old boy of Afro-Caribbean extraction who has been followed for 12 years with repeat biopsies. He initially presented at 5 years of age with swelling of the left upper eyelid, left cervical lymphadenopathy, and eosinophilia. One year later he developed swelling of the right upper eyelid. There has been no change in the clinical appearance over the next 12 years. Repeated biopsies of the eyelids showed a diffuse inflammatory infiltrate with many eosinophils and lymphocytes. A lymph node biopsy showed reactive lymphoid hyperplasia. Immunohistochemistry using lymphoid markers showed a polyclonal pattern. Kimura's disease is a rare cause of eyelid swelling, particularly at such a young age and with bilateral involvement. This case demonstrates that bilateral orbital lymphoid lesions with cervical node involvement do not always imply lymphoma, but may have a benign pathogenesis. The unusually long follow up in this case confirms an excellent prognosis for Kimura's disease with conservative management. Accurate diagnosis in small orbital biopsies may spare the patient unnecessary radical surgery. (Brf Ophthalmol 1992; 76: 755-757)
\end{abstract}

Kimura's disease is a chronic inflammatory condition occurring predominantly in orientals, with occasional cases reported in Caucasians, and rarely in blacks..$^{1-5}$ To our knowledge it has not been reported previously in a person of Caribbean extraction. The first description appeared in the Chinese literature in $1937^{\prime}$ as 'eosinophilic hyperplastic lymphadenopathy', but the disorder became popularly known as Kimura's disease following the report of photograph of the patient showing bilateral swollen eyelids, more severe on the left.

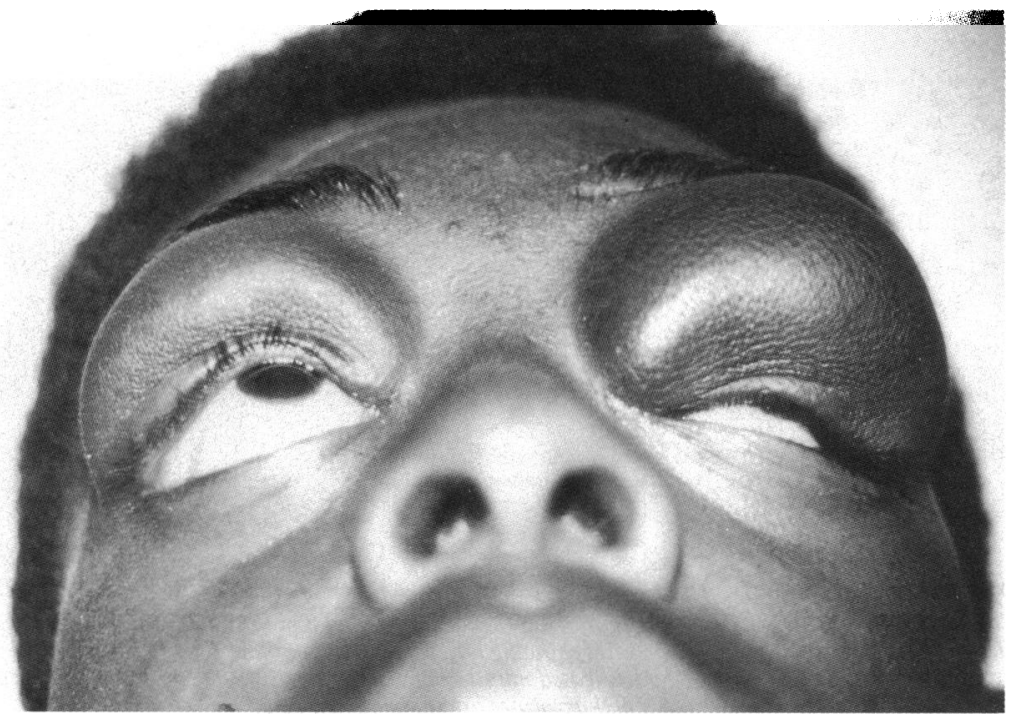

Kimura et al in the Japanese literature. ${ }^{2}$ Kimura's disease has a predilection for the head and neck region, but orbital involvement has been reported in only 14 cases..$^{5-11}$ Four of these patients had eyelid involvement. ${ }^{56}$ In only one patient ${ }^{5}$ was the disease bilateral. In the published literature on orbital disease there is little information on the long-term clinical behaviour or of the progressive histopathological changes which might occur. We had the opportunity to study repeat biopsies in the Afro-Caribbean boy over a period of 12 years and the findings are reported here.

\section{Case report}

A 5-year-old boy presented with swelling of the left upper lid and bilateral cervical lymphadenopathy. He was otherwise in good health and no other abnormalities were detected on ocular and general physical examination. Laboratory investigations included an ESR of $23 \mathrm{~mm} /$ hour, WBC of $10.6 \times 10^{9} / \mathrm{ml}$ with a differential of neutrophils $42 \%$, lymphocytes $41 \%$, monocytes $3 \%$, eosinophils $13 \%$, and basophils $1 \%$. The haemoglobin and platelet counts were normal. A biochemical profile, thyroid function tests, and serum calcium and albumin were normal. Serum electrophoresis showed a diffuse hypergammaglobulinaemia. HTLV 1 antibody titre was negative. An orbital computed tomographic (CT) scan showed diffuse swelling of the left lateral rectus muscle. A biopsy of the cervical lymph node showed a prominent eosinophilic infiltrate of follicles and interfollicular areas. This was interpreted as a benign inflammatory process. One year later swelling of the right eyelid became apparent. At that time both lids were almost symmetrically enlarged. The left eyelid was biopsied but there was no other surgical intervention. The child achieved normal growth and remained well despite the cosmetic handicap of grossly swollen eyelids. He noticed a variation in the size of his eyelids from day to day. At the age of 17 , the patient was reevaluated at his annual clinical examination. $\mathrm{He}$ was a healthy looking black male with massively swollen upper and lower eyelids (Fig 1). There was generalised swelling of the subcutaneous tissues of the eyelids, and firm discrete nodules were palpable, three on the right and two on the left (approximate maximal diameter $1 \mathrm{~cm}$ ). All were freely mobile and non tender. One of the right upper lid nodules was biopsied. Physical examination revealed no lymphadenopathy or organomegaly.

\section{Histopathologic findings}

Biopsy of the left upper eyelid was performed at the age of 6 years. An inflammatory infiltrate composed of eosinophilic polymorphonuclear 


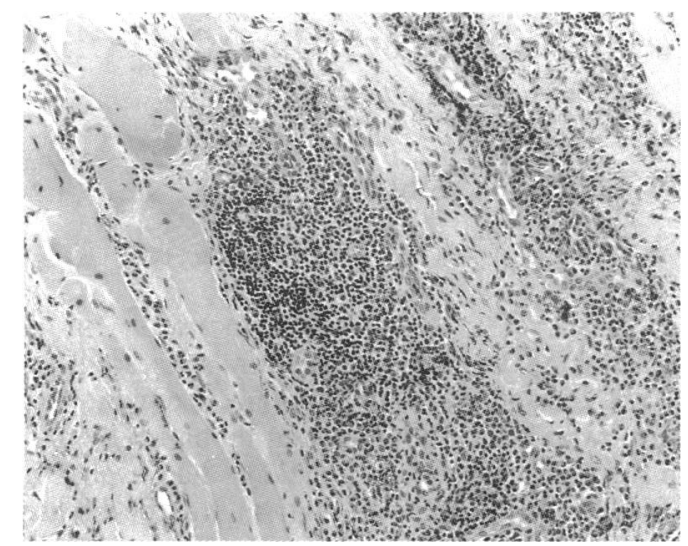

Figure 2 Extensive inflammatory infiltrate of striated muscle and fibroconnective tissue of the eyelid.

leucocytes, small lymphocytes, mast cells, and plasma cells was scattered throughout fibrous tissue and striated muscle (Fig 2). A few reactive lymphoid follicles were present. Degranulating eosinophils were particularly prominent around small blood vessels but there was no evidence of fibrinoid necrosis. The vessels had a slightly hyperplastic endothelial lining, but the epithelioid change and intracellular lumina which are typical of angioimmunoblastic lymphadenopathy were not seen (Fig 3). Clusters of eosinophils were present in the mantle zone of some follicles and occasional eosinophilic microabscesses were seen in the germinal centres (eosinophilic folliculolysis). The cervical lymph node showed follicular hyperplasia with multinuclear giant cells and eosinophils in germinal centres. Some eosinophils were degranulating. There was no evidence of atypia and ReedSternberg cells were not seen. Mitoses were confined to the germinal centres.

Biopsy of the right upper eyelid was performed 11 years later. It showed hyperplastic lymphoid follicles embedded in sclerotic fibroconnective tissue. The follicles were oval with a well defined eccentric mantle zone and prominent germinal centres. Polykaryocytes resembling WarthinFinkeldy type giant cells were conspicuous (Fig 4) both in germinal centres and mantle zones. These giant cells contained up to 25 nuclei clustered together. Numerous eosinophils were present in the soft tissue and lymphoid follicles. Sheets of eosinophils, many degranulating, and

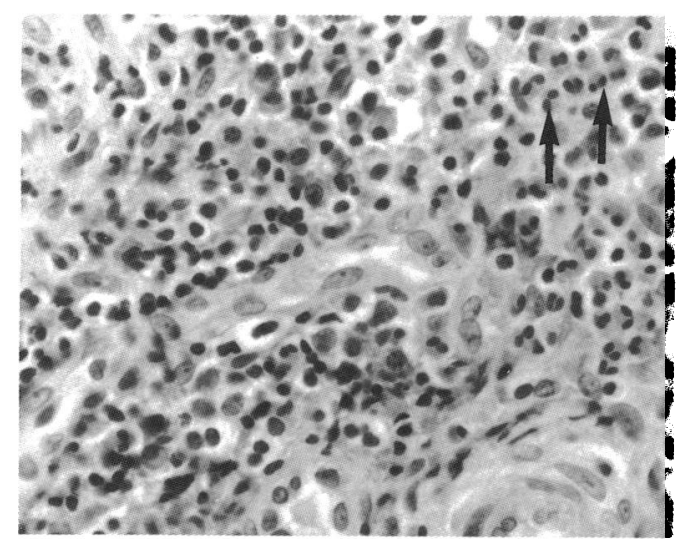

Figure 3 High power photomicrograph showing the predominance of the bilobed eosinophils (arrows) in the inflammatory infiltrate. A vessel with a hyperplastic endothelial lining is shown. small lymphocytes infiltrated striated muscle and fibrous tissues.

Immunohistochemical studies using monoclonal antibodies to $\mathrm{B}$ and $\mathrm{T}$ cell markers (L26 and UCHL1) and immunoglobulin (Ig) heavy and light chains (Dakopatts, Copenhagen, Denmark), the avidin-biotin-peroxidase complex $(\mathrm{ABC})$ method of $\mathrm{Hsu}^{12}$ and the Vector ABC kit (Vector Labs, Burlingame, CA, USA) revealed a polymorphic lymphoid infiltrate with the usual distribution of $B$ and $T$ cells. IgE staining was seen in lymphoid follicles and some plasma cells and mast cells. IgM and IgG positivity was also seen.

\section{Discussion}

Kimura's disease is an inflammatory process with a predilection for the head and neck region in young men histologically characterised by an angiolymphoid proliferation with eosinophilia and elevated serum immunoglobulin IgE. ${ }^{1-6}$ The aetiology is unknown and controversy exists as to whether it represents a benign lymphoid neoplastic process or is an allergic reaction. Evidence concerning the long-term behaviour of the disease is scanty. Although some authors use the terms Kimura's disease and angiofollicular lymphoid hyperplasia interchangeably, recent studies suggest that they may be different entities. ${ }^{12-15}$ Kimura's disease presents as a large solitary lump or multiple lumps, with an insidious onset, long duration, and a frequent occurrence of peripheral blood hypereosinophilia. Regional lymph node involvement occurs in up to $75 \%$ of cases. Systemic associations include asthma and the nephrotic syndrome.$^{614}$ Recurrence is common, estimated between $15 \%$ and $40 \%$ of cases, ${ }^{15}$ but fatalities have not been reported. By contrast, angiolymphoid hyperplasia is said to present with small papules or nodules on the face and scalp. On histological examination prominent hypertrophic vessels with swollen endothelial cells proliferating around arterioles and venules are seen; lymphoid proliferation is less apparent. Systemic abnormalities are not frequent.

Although Kimura's disease is most often periauricular or submandibular, a small number of orbital lesions have been reported on the basis of an isolated biopsy and very few cases have

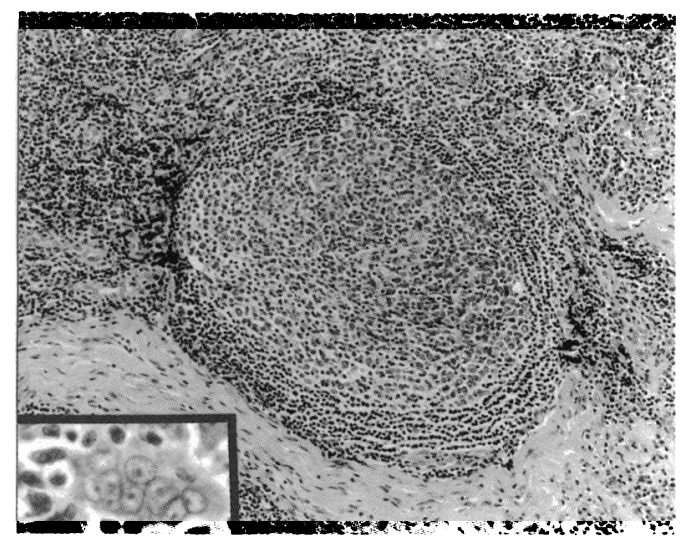

Figure 4 Haematoxylin and eosin stained section of the eyelid showing a hyperplastic lymphoid follicle, with a well delineated mantle zone. Warthin-Finkeldey type giant cells or polykaryocytes are shown in the inset. 
been followed over prolonged time interval. The first orbital cases were recorded in $1976,{ }^{4} 1979,5$ and $1982^{10}$. In 1983, a series of five orbital and three adnexal cases was published ${ }^{6}$ including a previously reported case. ${ }^{10}$ The mean age was 51 years (range 38-72), which is older than the mean age at other sites. Neither lid nor orbital disease have been reported in a child. The lesions were uniformly solitary and affected the eyebrow, superior orbital ridge, and roof of the orbit. The orbital nodules varied in size from $1 \cdot 2$ to $2.7 \mathrm{~cm}$ in maximal diameter. Those with an adnexal location comprised a solitary nodule at the inner canthus in one patient and the upper lid in two. These nodules were smaller (7-8 mm) than the orbital cases. Four orbital cases have been reported subsequently. ${ }^{7-911}$ In one of these ${ }^{8}$ the lesion arose in a patient who had undergone enucleation for malignant melanoma of the choroid, followed by an Iowa (polymethylmethacrylate) implant. The occurrence of Kimura's disease in this situation led the authors to suggest that the disease was a probable reaction to the implant. There have been no subsequent reports of Kimura's disease following orbital implants. The histopathological features described in the literature are similar to those seen in the present case - for example, eosinophilic infiltration of soft tissue, florid germinal centres, apparently increased postcapillary venules, and fibrous sclerosis. Giant cells of Warthin-Finkeldy type, which are more often associated with viral lymphadenopathies such as measles, were prominent in the germinal centres and the paracortex of our case. These cells have been noted by others in lymph nodes and salivary glands but not in the orbital cases affected by Kimura's disease. ${ }^{15-18}$

Ocular adnexal lymphoid proliferations can present clinical and histopathological problems and are well documented although there is much to learn. The finding of a mixed lesion composed of an eosinophilic and lymphocytic infiltrate, follicular hyperplasia, and fibrosis brings both orbital pseudotumour and Hodgkin's disease to mind. Inflammatory pseudotumours have a polymorphous inflammatory infiltrate composed of lymphocytes, plasma cells, and histiocytes with a hyalinised or oedematous stroma. Endothelial cells are hypertrophied and prominent. Eosinophils may be present but are not usually such a conspicuous feature as in this case. Although lymphoid aggregates may be seen, reactive germinal centres are a relatively uncommon feature. ${ }^{19}{ }^{20}$ Hodgkin's disease is ruled out by the lack of the diagnostic Reed-Sternberg cells and atypical mononuclear cells. Vessels are prominent, but there is no true vasculitis nor are there malignant cytologic features, so that systemic vascular disease is unlikely.

Previously reported cases of periorbital Kimura's disease were successfully treated with excisional biopsy. Hidayat et $a l^{6}$ reported excessive bleeding during surgery in one patient. Radiotherapy and intralesional steroids have not been tried in orbital disease. There has been some success with radiotherapy in skin disease. ${ }^{6}$ In our patient the untreated lesions slowly increased in size and there was continuing eosinophilia but no other haematological abnor- mality. Despite the CT evidence of lateral rectus involvement eye movement was normal. This pattern suggests a low grade, possibly aberrant, hypersensitivity or allergic response to a continuing antigenic stimulus. We have compared the early and late pathological features in the eyelid over a 12 year period and found a continuing active inflammatory reaction but no evidence of neoplasia. Eosinophils were just as numerous in the late biopsy.

Surgical treatment of large eyelid nodules may present difficult technical problems. In one report an orbital lesion underwent severe haemorrhage on resection. ${ }^{6}$ In such cases conservative management may be the best option, but should include biopsy and histopathological examination to rule out lymphoma.

In a large study of orbital and conjunctival lymphoid infiltrates, Medeiros and Harris ${ }^{21}$ state that bilateral involvement and dissemination, such as cervical lymphadenopathy, at the time of presentation, occur only in lymphomas. Our case disproves this statement, showing the importance of histopathological examination.

1 Kim HT, Scezo C. Eosinophilic hyperplastic lymphogranuloma, comparison with Mikulicz's disease. Chung Hua I Hsueu Tsa Chi (Chin Med F) 1937; 23: 699-700. (in Chinese.) 2 Kimura T, Yoshimura S, Ishikura E. On the unusual granulation combined with hyperplastic changes of lymphatic tissue. Trans Soc Pathol fpn 1948; 37: 179-80. (in Japanese.)

3 Chang T-L, Ch'en CY. Eosinophilic granuloma of lymph nodes and soft tissues. Report of 21 cases. Chin Med F 1962; 81: 384-7.

4 Takenaka T, Okuda M, Usami A, Kawabori S, Ogami Y, Kubo K, et al. Histochemical and immunological studies on eosinophilic granuloma of soft tissue called Kimura's disease. Clin Allergy 1976; 6: 27-35.

5 Dhermy P, Haye C, Dufier JL, Regnault F. L' Hyperplasie angio-lymphoide avec d'une localisation palpebral. $\mathcal{f} F r$ Ophtalmol 1979; 2: 247-52.

6 Hidayat AA, Cameron JD, Font RL, Zimmerman LE. Angiolymphoid hyperplasia with eosinophilia (Kimura's disease) of the orbit and ocular adnexa. Am $\mathcal{F}$ Ophthalmol 1983; 96: 176-89.

7 Francis IC, Kappagoda ME, Smith J, Kneale K. Kimura' disease of the orbit. Ophthalmic Plast Reconst Surg 1988; 4 : 235-9.

8 Smith DL, Kincaid MC, Nicolitz E. Angiolymphoid hyperplasia with eosinophilia (Kimura's disease) of the orbit. Arch Ophthalmol 1988; 106: 793-5.

9 Shields CL, Shields JA, Glass RN. Bilateral orbital involvement with angiolymphoid hyperplasia with eosinophilia ment with angiolymphoid hyperplasia

10 Bostad L, Pettersen W. Angiolymphoid hyperplasia with eosinophilia involving the orbit: a case report. Acta Ophthal mol 1982; 60: 419-26.

11 Conrads H, Bosse U. Angiofolliculare Hyperplasie mit Eosinophilie (Kimura's disease). Fortschr Ophthalmol 1987; 84: 489-90.

2 Hsu SM, Raine L, Fanger H. The use of avidin-biotinperoxidase complex (ABC) in immunoperoxidase technics: comparison between $\mathrm{ABC}$ and unlabeled antibody (PAP) procedures. $\mathcal{F}$ Histochem Cytochem 1981; 29: 577-80.

13 Rosai J, Gold J, Landy R. The histiocytoid hemangioma. Human Path 1979; 10: 707-30.

14 Kung ITM, Gibson JB, Bannatyne PM. Kimura's disease: a clinicopathologic study of 21 cases and its distinction from angiolymphoid hyperplasia with eosinophilia. Pathology 1984; 16: $39-44$.

15 Kuo TT, Shih HY, Chan HL. Kimura's disease: involvement of regional lymph nodes and its distinction from angiolymphoid hyperplasia with eosinophilia. Am f Surg Path 1988; 12: 843-54.

16 Chan JKC, Hui PK, Ng CS, Yuen NWF, Kung ITM, Gwi E Epithelioid haemangioma (angiolymphoid hyperplasia with eosinophilia) and Kimura's disease in Chinese. Histopathology 1989; 15: 557-74.

17 Hui PK, Ng CS, Kung ITM, Gwi E. Lymphadenopathy of Kimura's disease. Am $\mathcal{Y}$ Surg Path 1989; 13: 177-86.

18 Tham KT, Leung PC, Saw D, Gwi E. Kimura's disease with salivary gland involvement. Br 7 Surg 1981; 68: 495-7.

19 Knowles DM, Jakobiec FA. Ocular adnexal lymphoid neoplasms: clinical, histopathologic, electron microscopic, and imm.

20 Lee WR, McGhee CNJ. Pseudotumours in the orbit. Recent Adv Histopathol 1989; 14: 123-37.

21 Medeiros LJ, Harris NL. Lymphoid infiltrates of the orbit and conjunctiva. A morphologic and immunophenotypic study of 99 cases. Am $\mathcal{F}$ Surg 1989; 13: 459-71. 